\title{
Web-based computational chemistry
}

\section{A Entzian*, S Haase and H Bögel}

Address: Institute of Chemistry, Martin-Luther-University, Halle-Wittenberg, 06120 Halle, Germany

* Corresponding author

from 4th German Conference on Chemoinformatics

Goslar, Germany. 9-II November 2008

Published: 5 June 2009

Chemistry Central Journal 2009, 3(SuppI I):P9 doi:I0.II86/I752-I53X-3-SI-P9

This abstract is available from: http://www.journal.chemistrycentral.com/content/3/SI/P9

(c) 2009 Entzian et al; licensee BioMed Central Ltd.

With the establishment of web applications and user-generated content under the concept of Web 2.0, the data stream increases in the direction to the Internet. The possibility of not having to collect and store data locally anymore, but to work centralized on the web offers a remarkable amount of new applications and teamwork in science. To use software and data on a server, reduces the need for local installation and administration. Another aspect is the possibility to use the efforts of collaborative work optimally. Platforms for the aggregation of knowledge, so called Wikis, are the future. Thus in computer chemistry the arrangement of input-data, the calculations and the graphical representation and interpretation of the results can be done on a server.

The web-based interface WebMO forms a common interface for the management and treatment of calculations ranging from Molecular Mechanics up to ab initio Quantum Mechanics. We have curried out e.g. investigations of the electronic structure of the a series of 20 canonical amino acids by using methods of the Density Function Theory (DFT), the semi-empirical MO methods like PM6 and AM1 (MOPAC), and MSINDO [1].

The characteristic features of the amino acids, obtained by these calculations like stabilisation energies, electron densities, atomic charges, dipole moments and frontier orbital energies were compared and evaluated for classification with different methods of data analysis.

The semi-empirical Molecular Orbital approximation MSINDO has some interesting features: parameters for $3 \mathrm{~d}-, 4 \mathrm{~s}$ - and $4 \mathrm{p}$ - valence orbitals of all $3 \mathrm{~d}$-transition metals are included and it is possible to run Molecular Dynamic simulations, useful for search of stable conformations and chemical reactions.

The mediaWiki software on which also Wikipedia is based offers the possibility to store and collect and publish the results of these calculations and other relevant information in a structured way. In this manner, teamwork without local restrictions is possible. Everything the user needs is internet access and a web browser equipped with current plug-ins like Flash and Java. The use of such an infrastructure is very helpful for lectures and exercises. We found that this new type of teamwork was very well accepted by the students as a part of e-learning.

\section{References}

I. Bredow T, Geudtner G, Jug K: MSINDO Parameterization for Third-Row Transition Metals. J Comput Chem 200I, 22:86I-887. 